\title{
Screening for psykisk utviklingshemning hos voksne
}

\begin{abstract}
Sammendrag
Bakgrunn. Å finne de riktige tiltakene for en person med psykisk utviklingshemning er ofte betinget av at diagnosen er stilt. Formålet med artikkelen er å belyse hvorvidt Hayes Ability Screening Index (HASI) egner seg for å fastslå psykisk utviklingshemning hos voksne.
\end{abstract}

Materiale og metode. Artikkelen er basert på tre tidligere studier der HASI er søkt validert - et poliklinisk utvalg som var henvist for nevropsykologisk spesialistvurdering, et utvalg av fengselsinnsatte og et utvalg av pasienter i sengeposter ved distriktspsykiatriske sentre.

Resultater. Utvalget totalt besto av 264 personer. HASI korrelerte statistisk signifikant med anerkjente og mer omfattende instrumenter for vurdering av intellektuell fungering (Wechslertester) ( $r=0,73, p<0,001)$. Med en grenseverdi på 85 hadde HASI en sensitivitet på $97 \%$ og en spesifisitet på $61 \%$ i forhold til $I Q<70$.

Fortolkning. HASI gir få falskt negative utfall, men mange falskt positive. Dette medfører at indikasjonen om psykisk utviklingshemning blir knyttet til altfor mange, ettersom et positivt screeningresultat skal følges opp med grundigere kartlegging.

\section{Erik Søndenaa}

erik.sondenaa@stolav.no

Kompetansesenteret for sikkerhets-,

fengsels-og rettspsykiatri

Avdeling Brøset

St. Olavs hospital

Postboks 1803 Lade

7440 Trondheim

\section{Olav Linaker}

Avdeling for forskning og utvikling psykisk helsevern

St. Olavs hospital

og

Voksenpsykiatri og medisinske atferdsfag

Institutt for nevromedisin

Norges teknisk-naturvitenskapelige universitet

\section{Tale Gjertine Bjørgen}

Kompetansesenteret for sikkerhets-

fengsels-og rettspsykiatri

Avdeling Brøset

St. Olavs hospital

og

Psykologisk institutt

Norges teknisk-naturvitenskapelige universitet

Jim Aage Nøttestad

Kompetansesenteret for sikkerhets-,

fengsels-og rettspsykiatri

Avdeling Brøset

St. Olavs hospital

Psykisk utviklingshemning innebærer mangelfull læringsevne samt manglende evne til å nyttiggjøre seg kunnskaper på en adekvat måte. Ofte innebærer diagnosen omfattende og langsiktige støttetiltak i form av omsorg og habilitering. For å kunne sette i verk riktige og nødvendige tiltak er det imidlertid ofte en betingelse at diagnosen er stilt. Sentrale myndigheter overfører dessuten penger til kommunene ut fra innrapportert antall psykisk utviklingshemmede.

I ICD-10 er psykisk utviklingshemning definert som «en tilstand med stagnert eller mangelfull utvikling av evner og funksjonsnivå, som viser seg i utviklingsperioden». Fire kategorier angir graden (lett, moderat, alvorlig og dyp), og siden diagnosen uttrykker avvik fra det vanlige, vil overgangen fra normal tilstand til lett grad av utviklingshemning (IQ 50-69) være flytende. IQ-testing, adaptiv funksjonstesting og omfattende anamnese blir anbefalt som del av utredningen (1). Ettersom psykisk utviklingshemning er en livslang tilstand, trengs det et betydelig sammensatt kartleggingsarbeid før diagnosen blir stilt (1).

I dag foreligger det flere tester der hensikten er å gi en rask screening av kognitive fer- digheter, men kun et fåtall av dem er oversatt til norsk og godt etablert innenfor norsk testtradisjon. Wechsler Abbreviated Scale of Intelligence (WASI) (2) foreligger i norsk utgave $(3,4)$. Den inneholder to deltester for verbal IQ og to deltester for utførings-IQ. Disse likner på deltester fra fullskalainstrumentet Wechsler Adult Intelligence Scale III (WAIS-III), som også finnes på norsk (5). WAIS III er betydelig mer omfattende enn WASI. For Kaufmann Brief Intelligence Test (K-bit) finnes det ikke noe norsk normmateriale (6). Mini-Mental State Examination (MMSE) er en rask screening av kognitive forhold. Den ble i utgangspunktet laget i tilknytning til demensutredning (7).

Selv om de ovennevnte testene er å foretrekke, har de på ulike måter svakheter - ved at de enten er tidkrevende å administrere, krever særlig opplæring/kompetanse, ikke har noe godt normgrunnlag eller ikke er laget for å fange opp generelt evnenivå, men skal avdekke spesifikke symptomer.

The Hayes Ability Screening Index (HASI) ble utviklet av Susan Hayes i 2000 som følge av at lovbrytere med utviklingshemning ikke ble identifisert og derfor i liten grad fikk tilrettelagt og tilgjengelig støtte (8). Utredning av utviklingshemning ble i hovedsak gjort $i$ de tilfeller der det var påfallende atferdsproblemer, ikke der personen var preget av tilbaketrekning eller unnvikelsesatferd eller hadde en tilsynelatende adekvat opptreden (9). HASI er funnet egnet innen strafferetten som en kortfattet screeningtest for å finne dem som trenger en mer omfattende utredning med tanke på ev. utviklingshemning (10). Utgangspunktet er at den skal være lett å bruke, rask å gjennomføre (5-10 minutter) og anvendbar for ulike

\section{Hovedbudskap}

- HASI er en screeningtest for identifisering av personer med psykisk utviklingshemning

- HASI korrelerte med mer omfattende instrumenter for vurdering av intellektuell fungering

- Et høyt antall falskt positive resultater ved bruk av HASI krever utvikling av mer presise tester

- Manglende diagnose kan begrense mulighetene til å gi likeverdig, effektiv og tilpasset støtte 
Tabell 1 Alder og testskårer i tre utvalg $(n=264)(12-14)$

\begin{tabular}{lcccc} 
& Gjennomsnitt & $95 \% \mathrm{KI}$ & Minimum & Maksimum \\
\hline Alder (år) & 35,6 & $34,1-37,1$ & 17 & 72 \\
\hline HASI & 82,5 & $81,1-83,9$ & 49,2 & 96,4 \\
\hline WAIS-III/WASI & 88,7 & $86,6-90,9$ & 45 & 129 \\
\hline Verbal & 85,1 & $83,0-87,2$ & 45 & 127 \\
\hline Utføring & 94,4 & $92,3-96,6$ & 47 & 129
\end{tabular}

kompetansegrupper. Samtidig har man funnet at HASI korrelerer godt med instrumenter for intelligenstesting og instrumenter for måling av adaptiv funksjon $(10,11)$.

HASI inneholder fire deltester - noen innledende bakgrunnsopplysninger, baklengsstaving av et ord på fem bokstaver, en problemløsningsoppgave og klokketegning. Deltestene er satt sammen ut ifra målsettingen om å bygge opp et instrument som oppfyller krav til presisjon, tilgjengelighet og tidsbesparelser (9).

Formålet med studiene som presenteres her, har vært å validere HASI for å vurdere om den kan brukes som en enkel grovkartlegging for å avdekke behov for videre undersøkelser av intellektuell funksjonsevne. I denne artikkelen slår vi sammen funn fra tre tidligere studier der HASI i norsk oversettelse har vært utprøvd i ulike utvalg (12-14).

\section{Materiale og metode}

Måleinstrumenter WASI og WAIS-III. HASI ble oversatt til norsk av Erik Søndenaa, oversatt tilbake til engelsk av en profesjonell translatør, for så å bli gjennomgått og godkjent av Susan Hayes. For delstudie 1 ble HASI og WAIS-III benyttet, i delstudie 2 og delstudie 3 ble WAISIII erstattet med WASI. Testene ble presentert i tilfeldig rekkefølge.

HASI er begrenset til å identifisere personer med nedsatt intellektuell fungering (IQ < 100). Høyeste oppnåelige skår for
Tre instrumenter ble brukt i studiene: HASI,
WAIS-IIIMASI

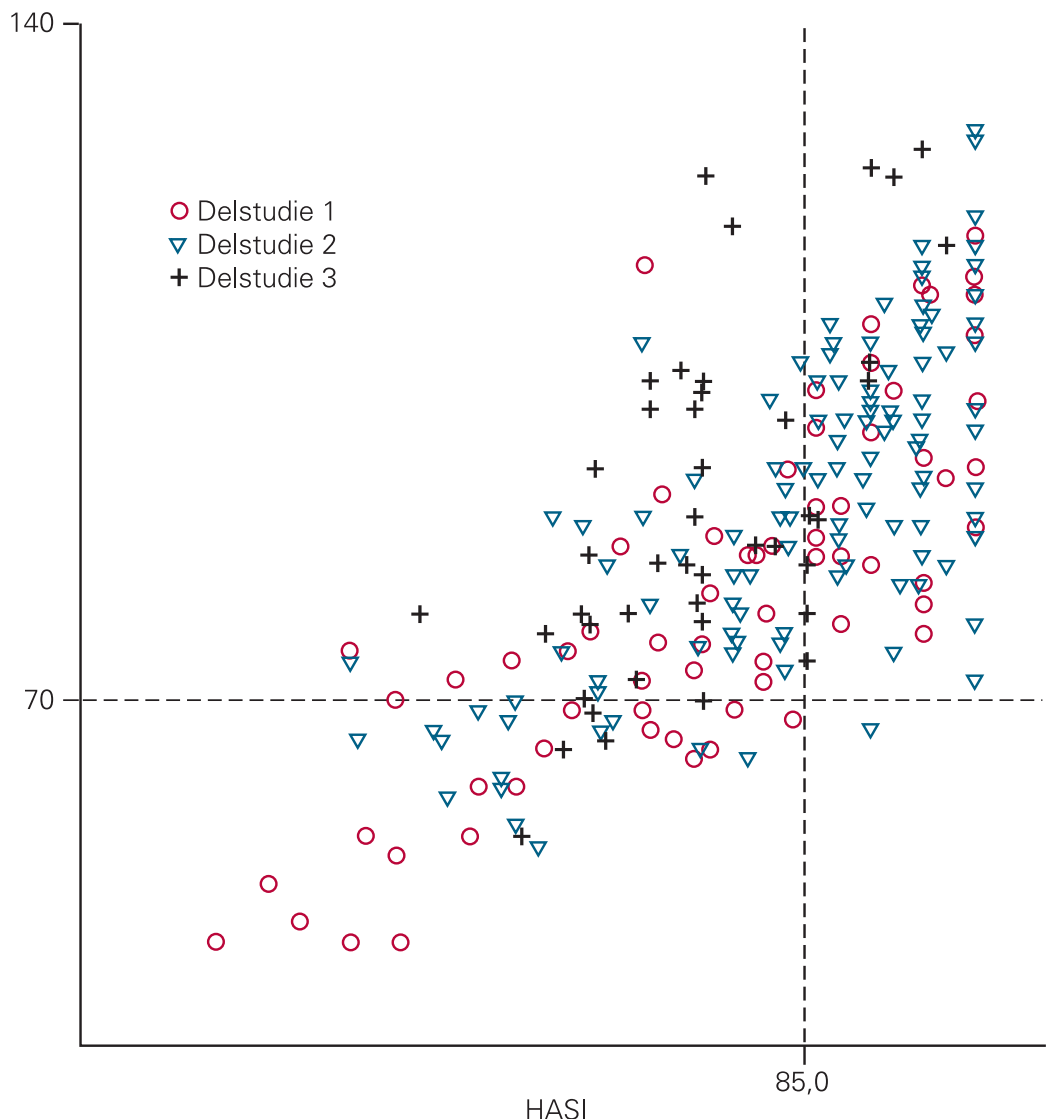

Figur 1 Samvariasjon av skårer fra HASI og WAIS-III/WASI i tre utvalg ln = 264) (12-14)
HASI er 96,4, laveste skår er 45,7 (ikke IQ). Både WAIS-III og WASI angir IQ-skår for et normativt utvalg hvor skårene spenner fra 45 til 160. Ettersom utvalget i studiene inkluderte personer med IQ-skårer over 100, vil naturlig nok HASI ligge noe lavere enn Wechsler-testene både for gjennomsnittsverdier og variasjon. Dette begrenser også korrelasjonsmålene mellom skalaenes skårer. Vi undersøkte hvorvidt HASI korrelerte med WASI og WAIS-III behandlet under ett.

\section{Bakgrunn og deltakere}

Artikkelen er basert på en samleanalyse av tre delstudier fra ulike omgivelser. Delstudie 1 (12) omfattet et poliklinisk utvalg som var henvist for nevropsykologisk spesialistvurdering, deltakerne i delstudie 2 (13) var et randomisert utvalg fengselsinnsatte og delstudie 3 (14) omfattet pasienter i sengeposter ved distriktspsykiatriske sentre.

\section{Datainnsamling og analyse}

Etter godkjenning fra regional etisk komité og Norsk samfunnsvitenskapelig datatjeneste (NSD) ble data samlet inn i perioden 2006-08. Analyse av samvariasjon og reliabilitet ble gjort med SPSS versjon 15 .

\section{Resultater}

De tre delstudiene omfattet henholdsvis 73 , 143 og 48 personer, til sammen 264. Det var 204 menn og 60 kvinner. Den skjeve kjønnsfordelingen skriver seg primært fra delstudie 2. Alder og testresultater er fremstilt i tabell 1.

Samvariasjonen (Pearsons r) mellom HASI og WAIS-III/WASI var $0,73(\mathrm{p}<0,001)$. Intern reliabilitet (Cronbachs $\alpha$ ) ble beregnet på bakgrunn av deltestene i HASI $(\alpha=0,77)$. Figur 1 viser hvordan testene HASI og WAIS-III/WASI samvarierer.

HASI viste en sensitivitet på 0,97 og en spesifisitet på 0,61 ved oppgitt grenseverdi av HASI på 85 i forhold til IQ $<70$. Antall falskt positive testresultater var 87 . Ved å sette ned grenseverdien for positiv screening fra 85 til 81, ble sensitiviteten 0,95 og spesifisiteten 0,72 (data ikke vist).

\section{Diskusjon}

Funnene viser at HASI korrelerer statistisk signifikant med Wechsler-testene. Av tabell 1 ser vi at deltakerne skårer svakere på de verbale testene enn på utføringstestene på WASI/WAIS-III. Denne forskjellen skriver seg primært fra delstudie 2. Behandling av WASI og WAIS-III under ett gjøres normalt ikke, men i nasjonale studier er det funnet at testene samvarierer (15).

HASI vil ikke være følsom for skårer i det øvre sjiktet (IQ>100), til forskjell fra WASI/WAIS-III. Disse målingene vil således stå mellom varierende WASI/WAIS-IIIskårer og maksimumsskårer fra HASI, noe som fremgår av figur 1. Det forholdet at HASI ikke dekker hele variasjonen av IQskårer, kan ha bidratt til at samvariasjonen ikke er høyere enn $r=0,73$. Grenseverdien 
for HASI på skår 85 gir et uforholdsmessig høyt antall falskt positive. Selv med en lavere grenseverdi, på 81, som vi har foreslått både for habiliteringsutvalget og for de fengselsinnsatte, vil det likevel være et høyt antall som blir antatt å være psykisk utviklingshemmet uten at dette er tilfellet. Dette problemet kan i en allmennlegepraksis muligens løses ved å forankre screeningen i typiske kjennetegn for mennesker med psykisk utviklingshemning (16) - at det er vanskelig å innhente sykdomshistorikk, at pasienten har en uklar formidling av helseproblemer og vansker med oppfølgingsavtaler eller det kan være praktiske hindre som manglende økonomi til kjøp av legemidler.

En rekke argumenter taler for screening, likevel finnes det viktige argumenter imot. Dersom man vet at det foreligger psykisk utviklingshemning, kan man gripe inn tidlig ved forståelsessvikt, manglende orienteringsevne, misforståelser og stor påvirkbarhet. Grunnlag for å etablere tiltakskjeder vil kunne komme som følge av at psykisk utviklingshemning blir screenet. I beste fall vil pasienten få tilrettelagte tjenester som sikrer vedkommendes rettigheter og øker effekten av rehabiliteringen. Positivt screeningresultat skal $i$ alle tilfeller ledsages av grundigere nevropsykologiske utredninger.

Ett av problemene med HASI er mange falskt positive utfall, og selv om det blir færre når grenseverdien justeres fra 85 til 81, blir begrepet «psykisk utviklingshemning» knyttet til altfor mange. Det er sannsynligvis heller ikke kapasitet til å utrede alle med positivt screeningresultat videre. Bruk av HASI kan også sette søkelys på en svikt som den det gjelder ikke alltid ønsker utredet. Det er et viktig moment at de mulige tiltakene som bør ledsage positive funn, er hjemlet innenfor dagens systemer. Helselovene, pasientrettighetsloven og sosialtjenesteloven med forskrift om «individuell plan» kan komme til anvendelse, og mulighetene for å legge til rette for økt selvstendighet og integritet vil dermed bli bedre.

Oppgitte interessekonflikter: Ingen

Litteratur

1. Offernes N, Lorentzen E. Diagnostisering av utviklingshemming hos voksne. I: Eknes J, Bakken TL, Løkke J et al, red. Utredning og diagnostisering: utviklingshemning psykiske lidelser og atferdsvansker. Oslo: Universitetsforlaget, 2008.

2. Wechsler D. Wechsler abbreviated scale of intelligence manual. San Antonio, TX: Harcourt Brace \& Company, 1999.

3. Brager-Larsen LM, Sundet K, Engvik H et al. Psychometric properties of a Norwegian research version of the Wechsler Abbreviated Scale of Intelligence (WASI). Bull Norw Neuropsychol Assoc 2001; 4: 70

4. Sundet $K, \emptyset$ rbeck B, Brager-Larsen LM et al. Wechsler Abbreviated Scale of Intelligence (Norwegian version). Oslo: Universitetet i Oslo, 2000-01.

5. Wechsler D, Nyman H, Nordvik H. WAIS-III: Wechsler Adult Intelligence Scale: manual (Norwegian edition). Stockholm: Psykologiförlaget, 2003.

6. Kaufmann AS, Kaufmann NL. Kaufmann Brief Intelligence Test Manual. Circle Pines, MN: American Guidance Service, 1990.
7. Folstein MF Folstein SE, McHugh PR Mini-Mental State: a practical method of grading the cognitive state of patients for the clinican. J Psychiatr Res 1975: 12: 189-98.

8. Hayes S, Craddock G. Simply criminal. 2. utg. Sydney: The Federation Press, 1992.

9. Hayes S. Hayes Ability Screening Index. Manual. Sydney: Faculty of Medicine, University of Sydney, 2000

10. Hayes S. Early intervention or early incarceration? Using a screening test for intellectual disability in the criminal justice system. J Appl Res Intellect Dis 2002; 15: $120-8$

11. Sparrow S, Balla D, Cicchetti D. Vineland Adaptive Behavior Scales. Circle Pines, MN: American Guidance Service, 1984.

12. Søndenaa E, Bjørgen TG, Nøttestad JA. Validation of the Norwegian version of Hayes Ability Screening Index for mental retardation. Psychol Rep 2007: 101: 1023-30.

13. Søndenaa E, Rasmussen K, Palmstierna T et al. The prevalence and nature of intellectual disability in Norwegian prisons. J Intellect Disabil Res 2008 . 52: 1129-37

14. Søndenaa E, Nygård $\emptyset$, Nøttestad JA et al. Validation and adaptation of the Norwegian version of the Hayes Ability Screening Index for intellectual disabilities in a psychiatric sample. Nord J Psychiatry 2010; e-publisert 14. mai.

15. Bosnes O. Klinisk utprøving av norske versjoner av noen sentrale tester på kognitiv funksjon. Doktoravhandling. Trondheim: Norges teknisk-naturvitenskapelige universitet, 2008

16. Lennox NG, Diggens JN, Ugoni AM. The general practice care for people with intellectual disability: barriers and solutions. J Intellect Disabil Res 1997 41: $380-90$

Manuskriptet ble mottatt 15.5. 2009 og godkjent 29.4. 2010. Medisinsk redaktør Siri Lunde. 